\title{
COMMUNICATION FROM THE EXPRESSION QUALITIES SYSTEM PERSPECTIVE
}

The focus of this paper is to state a categorization of expressions for a qualitatively correct media communication. For our starting point, we have chosen the systematic categorization of aesthetic expression qualities based on the pragmatic aesthetics by Professor Frantisek Miko, which also constitutes the main scope of research for Institute of Literary and Art Communication at the Faculty of Arts of Constantine the Philosopher University in Nitra. However, our aim is to extend the original applicability of the aesthetic expression qualities categorization outside the artistic and aesthetic reality specifically for the use in the mass media environment. In other words, we aim to develop the existing methodology of the expression qualities system of the modern aesthetic categories - the so-called Nitra pragmatic aesthetics - on a media platform for the study of communication.

Keywords: Expression qualities system, aesthetic categories, iconicism, operability, recipient.

\section{Introduction}

Our adoption of the aesthetic expression qualities categorization merges two main theoretical concepts. Our principal term the expression category that can be traced back to the research material by Professor Miko - Thesaurus of aesthetic expression qualities published by Institute of Literary and Art Communication in Nitra in 2008 - is at the core of a modern perspective of the categorization of expressions as perceived by the recipient. Our extrapolation that understands the expression category as the quality of a media message, its pragmatic effect on its recipient, and its stylistic function with its information value in the general sense, follows the declared interdisciplinary characteristics, conceptual openness and accessibility of the original term [1].

The second theory is understandably the theory of communication which provides the necessary means to explain a qualitatively correct media message. Mathematician Claude E. Shannon in his study A Mathematical Theory of Communication for the first time introduced the term information entropy as the level of uncertainty with respect to the information contained in a specific message. In this ground-breaking Theory of information, which analyses the issue of coding, storing, and transmitting of information, other terms like redundancy, communication channel capacity, or bit as the basic information unit are also defined [2].
There are many factors that suggest the suitability of the extended application of aesthetic expression qualities within the media environment the way we propose in the following pages.

\section{Expression quality as a dynamic factor of communication}

In our perception, the expression categories are represented in the form of diverse stylistically coloured adjectives of the full range of media messages in the consciousness of a recipient (addressee). In particular, however, in the form of a desired response largely determined by emotional characteristics of the recipient and author as well as the message. The original state is the recipient's empirical experience as it is subjected to the media message during its reception. Alternatively, the expression categories can be considered a synonym of the style in which the media information is presented to the recipient, where the "style is the result of the theme and language of the statement" [3] that is, what the message is about and how it was communicated. It should be mentioned at this point that Professor Miko himself sees the potential for a synonymic relationship between the terms expression category and semantic terms such as expression value, e. characteristics, e. modality, e. register, or expression mode [4]. After all, quite often the context of a conversation about a specific media artefact (such as a movie, an advertisement, a news report, a multimedia work on the web, etc.) with another subject transpires using questions such as How did it reflect on you?, or In

\footnotetext{
* Pavel Urban

Department of Pedagogical Studies, Faculty of Humanities, University of Zilina, Slovakia

E-mail: pavel.urban@fhv.uniza.sk
} 
what way/style was it directed or presented? The style can be, in the (media) communication practice, carried out in two distinct ways: a) The perceptual attributes of the artefact as perceived by the audience are dominant to the extent premeditated by the author during the creation process. In other words, the style of the author serves to deliberately provoke the audience to a certain (emotional) state; alternatively, its stylised elements serve to disrupt stereotype.

b) It projects the author's self-expression in such a way the external recipient - audience - is not taken into account. The author him/herself becomes both the addresser and the addressee of the communication.

As mentioned before, we originate in the model of the binary expression system methodologically developed by Professor Miko. The systematic consistency of this model lies in the fact that it is not only a sort of an inventory listing of aesthetic expression categories, but it is multifocally anchored in the principles of their interrelatedness. Furthermore, this systematic organisation is determined by principles of hierarchy further illustrating their similar or contradictory relations. From the pragmatic perspective this organisation documents the way the categories interact and connect while forming superior-inferior structures and framework blocks [5]. The primary expression qualities are arranged on the principles of binary opposition:

- operability - iconicism

- sensuality - factuality

- subjectivity - sociability

The competitive relationship between these three fundamental oppositions reflects the ever-present strengthening of one of the qualities from the pair at the expense of its partnered quality, e.g. "the increased subjectivity (a focus on self-expression such as expressing anger) weakens the sociability (caring for the recipient such as respect)" [6]. At the same time, both members of each of these pairs are complements on the principles of expression inclusion: "one of the categories is in a way broader, the second is its particular specialty" [7]. Keep in mind that the external manifestations of the individual expression categories are being expressed specifically through structural indicators - the verifiable signs of the existence and intensity of that particular "expression quality in the message" [8].

We now have identified the basic features according to which the model of the expression system works. The fundament of its applicability is the communication process which can be represented using the following generic model (Fig 1):

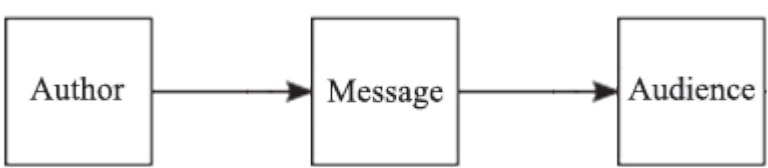

Fig. 1 General diagram of a communication process

\section{The structure of the general model of communication}

In general, we can say that human communication participates in the creation and regulation of a subject's behaviour in the way it directs the allocation of information because we communicate in order to receive data, or to exchange and modify it and, using such data, we perceive and can persuade thus potentially forming social ties. The theory of communication per se considers the communication process to be an interactive instrument for the exercising of power among its subjects who are connected through the belief in the same set of meanings across their social group. The general model of the communication transfer/process, which forms the base for other interdisciplinary schematic modalities of communication, can be altered to a model that we shall call $3 \mathrm{C}$ :

$$
\text { communicator - communiqué - communicant }
$$

(author/sender/expedient) - (transmission/message/data) - (recipient/audience)

Subject - communicator translates the information (concept, intention) into the communiqué which he/she aims to share with another subject - communicant using meaningful forms, that is, by encoding the information into the common communication language (verbal and/or non-verbal) and sharing it with its recipient over the communication channel. The recipient perceives the information through his/her senses and then decodes/ interprets it into a meaningful form. After the interpretation, the communicant responds in a specific way suitable for the particular communication environment thus completing the communication context of the communication process. The result of this information sharing is the understanding based on the perception of a certain "objective reality, as one of the ways in which the subject acts, his/her creative activity is manifested" [9]. One of the key components of this information exchange system is the feedback/response with its varying level of dynamics which shapes the entire communication process for the (most effective) acquisition of new knowledge. These new data lead to the changes in the state of understanding signifying the reduction of entropy in the communication system.

While analysing the theory of communication from the technical perspective, it is worth to mention the functional model describing the process of the information transfer as suggested by Claude E. Shannon in Fig. 2:

- An information source producing a specific (desired) message.

- A transmitter coding a message using the type of signal, which allows for as lossless transmitting across an information channel as possible.

- The information channel simply as the transitory medium which serves to distribute the signal.

- A Receiver decoding the signal back to the understandable form intended for perceiving.

- A Destination or the intended recipient of the message human or machine. 


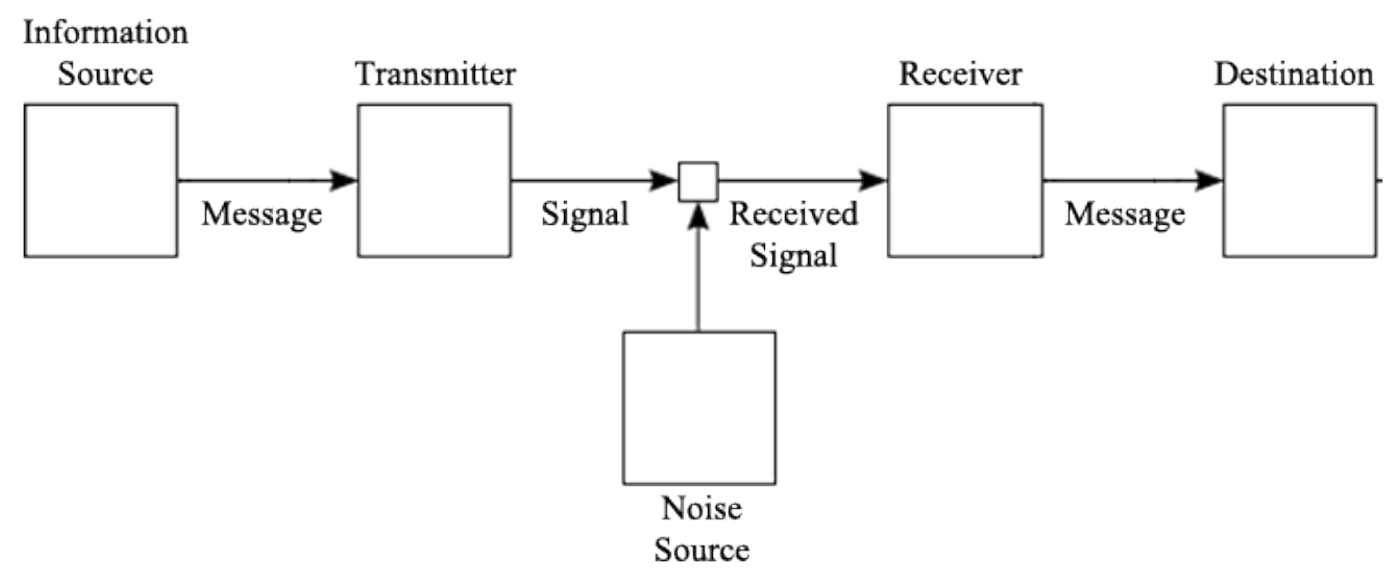

Fig. 2 Schematic diagram of a general communication system [10]

Before we return to the issue of the expression system, let us recall one more important phenomenon underlying the qualitatively, from the informational standpoint, correct communication. This phenomenon is the feedback which serves to diminish the level of entropy by allowing the participating subjects to reduce the volume of redundant and irrelevant data through the refinement of criteria for selecting, processing, and organising of the information reservoir.

\section{The core of the expression system - operability versus iconicism}

The key issue of the expression system, which resides in the interpersonal communication, concerns someone referring something to someone (else). This initial structure of communication consists of two aspects:

4.1 The first aspect pertains to the relation between someone - to someone (else), in other words, the relation author - audience where the message becomes the tool for exercising author's goal within the interaction. This focus on the interpersonal relationship between the participants in the communication is described by the first from the fundamental expression categories - the operability of an expression.

4.2 The second aspect pertains to the referential potential of the message - to express something by "projecting an image" of its meaning. The descriptor for this aspect is the second category - the iconicism of an expression.

The thesaurus methodologically places two fundamental categories across from each other creating the core of the whole expression system - operability (action) and iconicism (manner). Both communication dimensions are essential and in this relation equivalent, but operability still forms the base for the qualitatively correct communication while iconicism serves as its enriching component [11]. Further dynamics influencing the quality of the operability and iconicism of an expression follow the following principles:

4.2 The dynamics of the manifestation of the operability of an expression occur in two directions which are determined by the inner dialectics behind these key communication subjects: author (expedient) - audience (recipient)

4.3 This signifies on which participant's perspective the communication relies more:

a) If the emphasis is on the author, it is his/her temperament, social status, and the current emotional state, which prevail in the message. In other words, the author's stylised self-expression in the form of the subjectivity of an expression.

b) A different operability of communication brings an emphasis on the audience suggesting to whom the message is intended. For this approach, it is the audience's emotional state, social status, and temperament, which are crucial, but in the perception of the author. In other words, the attitude of the author towards the audience manifests in the form of the sociability of an expression.

4.4 The exposing of the iconicism of an expression has emerged from the historical context, within which an essential element represents the evolution of languages allowing their users to convey messages about phenomena which happened or might happen in the future. These messages can, e.g. through their verbal performance, "convey even such images the participant of the communication has not experienced directly, that is, it allows to free oneself from the immediate situation the communication takes place in" [12].

a) From this phenomenon evolved the capacity of language to generalize, specify, extrapolate, confront, prove, etc. This in turn began the application of pragmatic characteristics of language in the use of terms especially in sciences represented by the factuality of an expression. 
b) On the other hand, the sensuality of an expression evolved in other spheres of language use which allows for a certain mostly visual subjective experience in the audience of especially artistic communication.

\section{Conclusion - the simplified expression qualities system}

The interrelationship of the three fundamental oppositions as explained within the (media) communication paradigm finally leads us to the schematic representation of our simplified model of the expression system (Fig. 3) from the one originally suggested by Prof. Miko. Please note, that the original stylistic organisation of the expression qualities is conceived as a "paradigmatic model of text from the stylistic point of view" [13] allowing a systematic, but especially pragmatic orientation for the reception analysis of the language modalities used mostly in artistic text to amplify

the effect of its message. However, our paper demonstrates that the simplified model is suitable for the reception analysis of any qualitatively correct media communication.

SOCIABILITY

$$
\mid
$$

OPERABILITY<smiles>C1CCCCC1</smiles>

SUBJECTIVITY
FACTUALITY

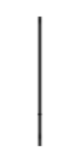

ICONICISM

Fig. 3 Simplified expression qualities system [14]

\section{References}

[1] PLESNIK, L. et al.: Thesaurus of Aesthetic Expression Qualities (in Slovak). Nitra : Univerzita Konstantina Filozofa, 2008, 474 p. ISBN 978-80-8094-350-9.

[2] SHANNON, C. E., WEAVER, W.: The Mathematical Theory of Communication [online]. Urbana : University of Illinois Press, 1949. [cit. 2014-02-10]. Available on the Internet: < http://raley.english.ucsb.edu/wp-content/Engl800/Shannon-Weaver.pdf>

[3] PLESNIK, L. et al.: Thesaurus of Aesthetic Expression Qualities (in Slovak). Nitra : Univerzita Konstantina Filozofa, 2008,18 p. ISBN 978-80-8094-350-9.

[4] MIKO, F.: Expression Aesthetics: Theory of Expression and Style (in Slovak). Bratislava : Slovenska pedagogicke nakladatelstvo, 1969, p. 16.

[5] PLESNIK, L. et al.: Thesaurus of Aesthetic Expression Qualities (in Slovak). Nitra : Univerzita Konstantina Filozofa, 2008,474 p. ISBN 978-80-8094-350-9.

[6] PLESNIK, L. et al.: Thesaurus of Aesthetic Expression Qualities (in Slovak). Nitra : Univerzita Konstantina Filozofa, 2008, 23 p. ISBN 978-80-8094-350-9.

[7] MIKO, F.: Expression Aesthetics: Theory of Expression and Style (in Slovak). Bratislava : Slovenske pedagogicke nakladatelstvo, 1969, $292 \mathrm{p}$.

[8] PLESNIK, L. et al.: Thesaurus of Aesthetic Expression Qualities (in Slovak). Nitra : Univerzita Konstantina Filozofa, 2008 , p. 20. ISBN 978-80-8094-350-9.

[9] CERNIK, V., FARKASOVA, E., VICENIK, J.: Theory of Knowledge (in Slovak). Bratislava : Nakladatelstvo Pravda, 1987, p. 12. ISBN 075-031-87.

[10] SHANNON, C. E.: A Mathematical Theory of Communication [online]. The Bell System Technical J., July/October 1948, vol. 27, pp. 379-423, $623-656$ [cit. 2014-02-10]. Available on the Internet: <http://cm.bell-labs.com/cm/ms/what/shannonday/shannon 1948.pdf>

[11] PLESNIK, L. et al.: Thesaurus of Aesthetic Expression Qualities (in Slovak). Nitra : Univerzita Konstantina Filozofa, 2008, 474, p. ISBN 978-80-8094-350-9.

[12] PLESNIK, L. et al.: Thesaurus of Aesthetic Expression Qualities (in Slovak). Nitra : Univerzita Konstantina Filozofa, 2008, p. 26, ISBN 978-80-8094-350-9.

[13] PLESNIK, L. et al.: Thesaurus of Aesthetic Expression Qualities (in Slovak). Nitra : Univerzita Konstantina Filozofa, 2008, p. 28, ISBN 978-80-8094-350-9.

[14] PLESNIK, L. et al.: Thesaurus of Aesthetic Expression Qualities (in Slovak). Nitra : Univerzita Konstantina Filozofa, 2008, p. 27, ISBN 978-80-8094-350-9.S 